\title{
The effect of chlorpromazine on the peak shift in the albino rat*
}

\author{
JOSEPH LYONS, WILLIAM D. KLIPEC, and RODNEY EIRICK \\ University of Arizona, Tucson, Arizona 85721
}

\begin{abstract}
Five groups of rats were given discrimination training between two different floor positions. Following mastery of the discrimination task, each group was tested for generalization along the floor tilt dimension. For half the Ss, Test 1 followed an injection of one of five dose levels, depending on the group, of chlorpromazine, followed by a second test with a saline control injection. The remaining Ss were tested in the reverse order, i.e., the saline test was first followed by the chlorpromazine test. The results indicate that the chlorpromazine reduced or eliminated the peak shift and reduced the area shift, but had little or no effect on discrimination performance. There was a strong dose-dependent effect.
\end{abstract}

Hanson (1959) introduced the term "peak-shift" to describe the finding that following discrimination training between two wavelength stimuli, pigeons respond more to a value beyond the $S+$ in the direction away from $\mathrm{S}$ - during a postdiscrimination generalization test. The peak-shift phenomenon in pigeons has been replicated many times, not only with the wavelength dimension, but also with other dimensions, e.g., floor tilt and line angle (cf. Terrace, 1966; Riccio, Urda, \& Thomas, 1966; Bloomfield, 1967; etc.).

In the Riccio et al (1966) study, one group of pigeons learned a discrimination between a horizontal floor (S+) and a 10-deg right floor tilt, i.e., clockwise (S-). Following mastery of the discrimination, the birds were tested for generalization to many different floor positions, including the $\mathrm{S}+$ and the $\mathrm{S}-$. The obtained gradients evidenced a strong peak-shift along this dimension with this experimental $\mathbf{S}$.

In a later study, Lyons, Klipec, and Steinsultz (1973) found that administration of the drug chlorpromazine, just prior to generalization testing, tends to reduce or eliminate the peak shift in pigeon Ss that show the peak shift in a control generalization test condition. However, Lyons et al (1973) found no tendency for discrimination performance to break down under the influence of the drug, as would be predicted on the basis of the Terrace (1963) study. In that study, it was found that administration of chlorpromazine produced a breakdown of discrimination performance in pigeon Ss that learned the discrimination with errors. Terrace assumed that discrimination performance was maintained by the buildup of inhibition to $S-$ as a result of nonreinforced responding in its presence. Administration of the drug, chlorpromazine, reduces or eliminates this inhibition, thereby producing a

*This research was supported by Grant 5T01 MH11286-04 from the National Institutes of Health to the Department of Psychology of the University of Arizona. We wish to thank Smith. Kline and French Laboratories for providing the drug, chlorpromazine. Requests for reprints should be sent to Joseph E. Lyons, Department of Psychology, University of Arizona. Tucson, Arizona 85721. breakdown in discrimination performance. Terrace (1963) also contends that this response-produced inhibition to $\mathrm{S}$ - produces the peak shift. However, the Lyons et al (1973) finding suggests that discrimination performance is maintained by a process different from the one that produces the peak shift. At this point, it should be noted that there were many procedural differences between the Terrace (1963) and the Lyons, Klipec, and Steinsultz (1973) studies. The most obvious of these was the fact that Terrace used a discrete trial procedure with continuous reinforcement, while Lyons et al used the free operant situation with VI reinforcement.

The purpose of the present study was to replicate the Riccio et al (1966) and the Lyons et al (1973) studies, but with the rat as the experimental $\mathrm{S}$. This was accomplished by demonstrating a peak shift along the floor tilt dimension with the rat as the $S$, then eliminating the peak shift by testing the rats under the influence of several dose levels of chlorpromazine.

\section{METHOD}

\section{Subjects}

The Ss were 20 male albino rats maintained at $70 \%$ of the weight of a free-feeding control group.

\section{Apparatus}

The apparatus consisted of four rat operant conditioning chambers constructed in such a way that the floor could be tilted $30 \mathrm{deg}$ (in 5-deg steps) in either direction from horizontal (cf. Fig. 1). All programming and recording equipment was the electromechanical type, and the noise of its operation was masked by a continuously present white noise.

\section{Procedure}

On Day 1, all Ss were barpress trained and given $50 \mathrm{CRF}$ for barpressing on this and the succeeding 2 days. On the following 3 days, the reinforcement schedule was gradually changed from CRF to a VI 1-min schedule. On Day 7, discrimination training was begun in the following way: Responding with the floor flat continued to be reinforced on the VI 1-min schedule, while responding with the floor tilted $30 \mathrm{deg}$ to the left 


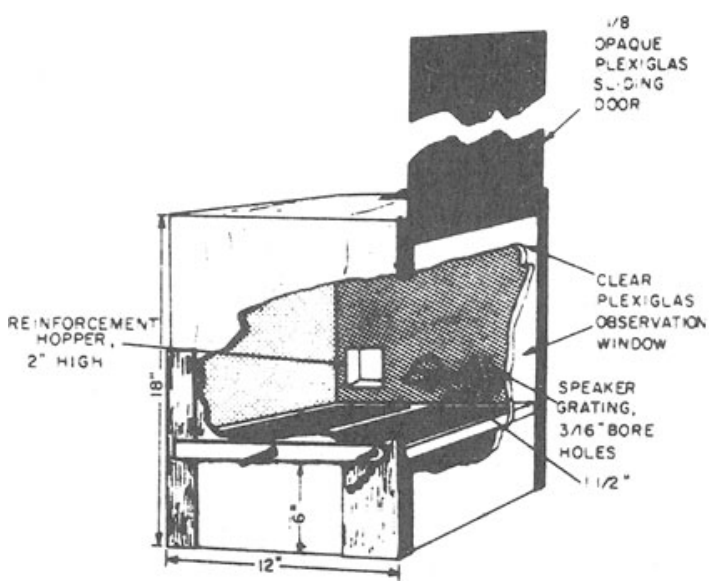

Fig. 1. Graphic represenation of the experimental chamber.

(counterclockwise) was extinguished. After attaining the criterion of seven responses to $S+$ for each response to $S-$ for 2 consecutive days, the $S$ - was changed to a $20-\mathrm{deg}$ left tilt and remained there to criterion performance. at which time the $\mathrm{S}$ was changed to $15 \mathrm{deg}$ until criterion was again obtained. This "fading" procedure was used because pilot work indicated that if discrimination training began with the $15-\mathrm{deg} \mathrm{S}-$. the rats failed to show any differential responding to $S+$ and $S-$. even after 90 training sessions. However, fading the $S-$ in from 30 deg greatly facilitated the learning of the discrimination task.

On the day following criterion performance with the 15-deg
$\mathrm{S}-$. all Ss were given the 5-min warm-up and a generalization test in extinction to 11 different floor tilts. including the $\mathrm{S}+$ and the $\mathrm{S}-$. Each $\mathrm{S}$ was tested in two conditions. either with a control injection of physiological saline or with an injection of one of five different dose levels of chlorpromazine hydrochloride in a physiological saline vehicle. All injections were delivered intraperitoneally 25-30 min prior to testing. Injection volume was constant for all dose levels. with the drug being prepared within 3 days of the test and refrigerated between administration. For half the Ss in each group, the saline test was first. followed by 3 days of retraining and a second generalization under the drug. For the remaining $10 \mathrm{Ss}$, the test conditions were reversed. There were four rats in each of the five dose levels used (1.0.1.5. 2.0, 2.5, and $3.0 \mathrm{mg} / \mathrm{kg}$ body weight).

Since the purpose of the study was to eliminate the peak shift with the drug. it was essential that all Ss utilized show the peak shift in the saline control condition. Consequently, rats failing to show a peak shift, defined as more responding to any angle to the right of the $S+$ than occurred to the $S+$ in the control test condition. Were dropped from the study. There were four such Ss. However. the lack of a peak shift in the control condition was not related to the order of test.

\section{RESULTS AND DISCUSSION}

For each $\mathrm{S}$, the measure of generalization used was the mean percent of total responses emitted in the presence of each of the test stimuli. The mean of these percents for the saline control condition and each of the

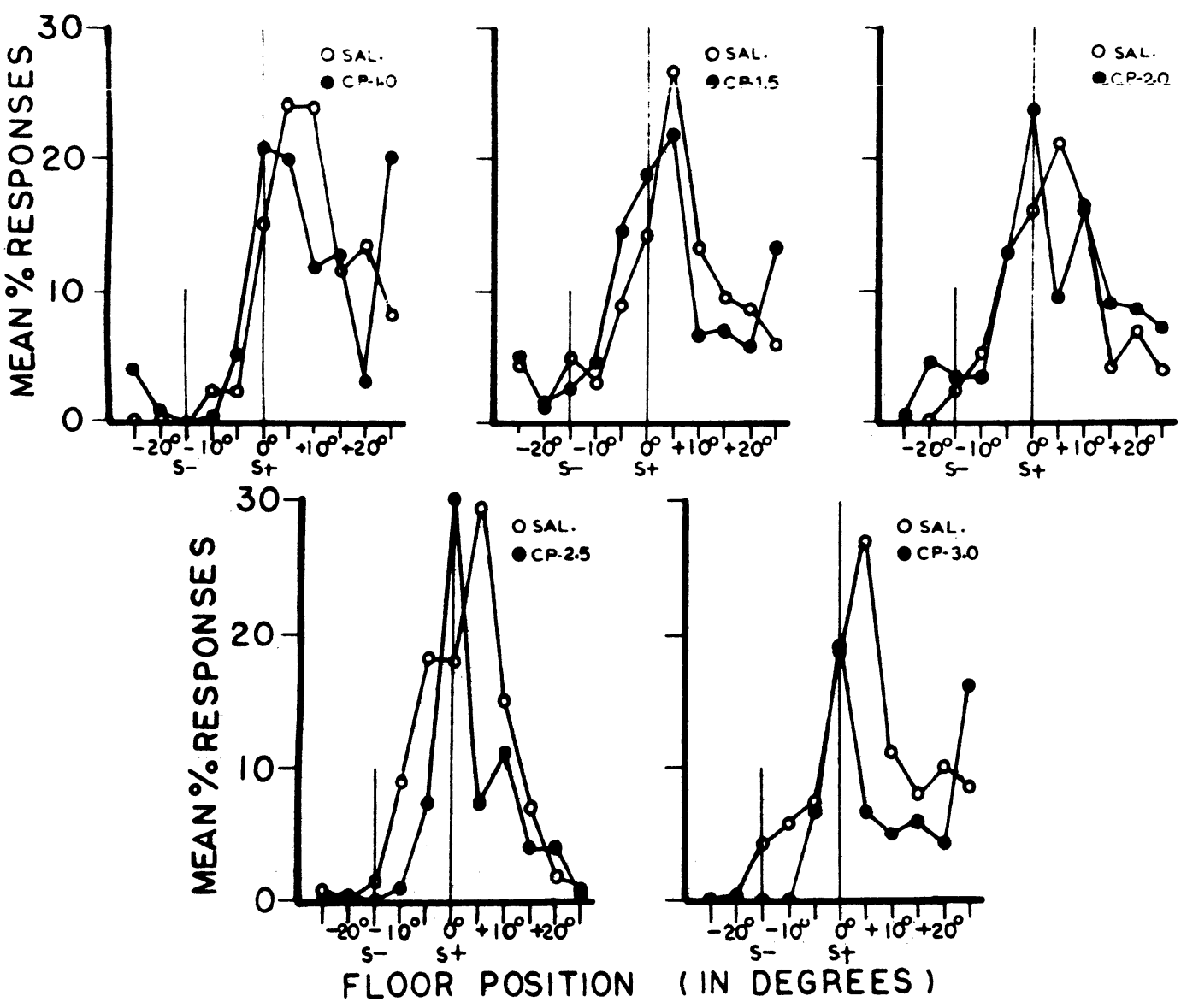

Fig. 2. The mean percent of total responses to each of the test stimuli in the saline control condition and in the five drug dose-level groups. 
five drug dose groups are presented in Fig. 2. Statistical analysis performed on these data indicated a highly reliable gradient in each of the six conditions (Fs from 5.09 to 31.04 : all $p$ values $<.01$ ). Further analysis with multiple comparisons showed a reliable peak shift in the saline control test condition, i.e., the rats responded more to the floor position $5 \mathrm{deg}$ to the right of horizontal than to the flat floor $[F(1,145)=27.89$, $\mathrm{p}<.001]$. The finding of a reliable peak-shift along the floor tilt dimension replicates the finding of Riccio et al (1966), but with the albino rat as the experimental S. A similar analysis performed on the data from the five different dose levels of the drug indicated that chlorpromazine completely eliminated the peak shift at the three highest dose levels, i.e., the rats responded more to the flat floor (S+) than to the 5-deg right floor tilt, the stimulus to which the peak shift occurred in the saline control condition [at $2.0 \mathrm{mg} / \mathrm{kg}, \mathrm{F}(1,29)=12.17$, $\mathrm{p}<.01$; at $2.5 \mathrm{mg} / \mathrm{kg}, \mathrm{F}(1,19)=8.64, \mathrm{p}<.01$; at $3.0 \mathrm{mg} / \mathrm{kg}, \mathrm{F}(1,19)=8.94, \mathrm{p}<.01]$. However, at the two lowest dose levels of the drug $(1.0$ and $1.5 \mathrm{mg} / \mathrm{kg})$, statistical analysis showed no reliable difference between the responding to the flat floor and to the 5-deg right floor tilt. This is true even though the graph suggests that at $1.0 \mathrm{mg} / \mathrm{kg}$ the peak shift is eliminated, while at $1.5 \mathrm{mg} / \mathrm{kg}$ the peak shift remains. In this case, the mean graph is misleading; in fact, in both the 1.0- and $1.5 \mathrm{mg} / \mathrm{kg}$ conditions, two of the three rats showed a peak shift under the drug. Thus, the effect of the two lowest dose levels of the drug on the peak shift is somewhat equivocal, but this is not the case at the three highest dose levels where the peak shift is eliminated by chlorpromazine.

In order to determine the effect of the drug on the area shift [i.e., the proportion of responses emitted to the side of the gradient to which the peak shift occurs and found by Lyons et al (1973) to be very sensitive to the effect of chlorpromazine], the percent of total responses to the St and the mean percent of total responses to the five test stimuli on the peak-shift side of the gradient in the saline control test condition were compared to the same two percents obtained while the rats were under the influence of the drug. With this measure, the area shift of the gradient is reflected in the magnitude of the mean percent of the total responses to the peak-shift side of the gradient relative to the percent of the responses emitted to S+. The higher this percent, the greater the area shift. The mean of these percent measures are presented in Fig. 3 for each of the six test conditions. An analysis of variance performed on these data indicated a highly reliable stimulus effect $[F(1,11)$ $=23.11, \mathrm{p}<.01]$, a reliable effect of the drug $[F(1,11)$ $=11.66, \mathrm{p}<.01]$, and a reliable Treatment (saline-drug) by Group (dose level) interaction $[F(4,11)=3.53$, $\mathrm{p}<.05]$.

Further analysis showed that under the drug the rats responded more to the $S+$ than to the peak-shift side of the gradient $[F(1.11)=14.06, p<.01]$, while there was

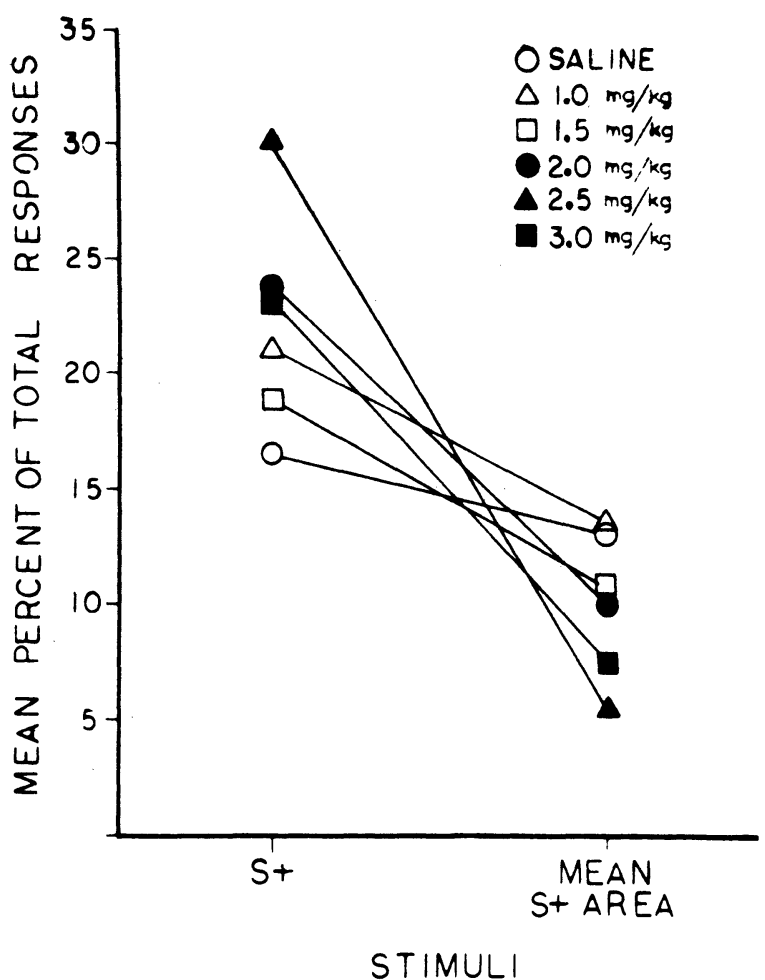

Fig. 3. Mean percent of total responses to the $S+$ and the mean of the mean percent of total responses to the peak-shift sides of the gradient.

no reliable difference in the relative response rate to these two values in the saline control condition. This suggests that the drug not only eliminates the peak shift, but also reduces the area shift. A comparison of the percent of total responses emitted in the presence of S+ with and without the drug confirms the increased control exerted by $\mathrm{S}+$ under the drug $[\mathrm{F}(1,11)=12.05$, $\mathrm{p}<.01]$.

Comparing the percent of total responses to the S+ among the five drug groups revealed a reliable progressive increase in the control exerted by S+ up to the $2.5 \cdot \mathrm{mg} / \mathrm{kg}$ dose level. However, the control exerted by $\mathrm{S}+$ at the $3.0-\mathrm{mg} / \mathrm{kg}$ dose level is reliably less than that produced by the $2.5 \cdot \mathrm{mg} / \mathrm{kg}$ dose level. [Comparing the percent to $\mathrm{S}+$ at the two lowest doses revealed no reliable difference between them; however, both demonstrated less control by S+ than did the $2.0-\mathrm{mg} / \mathrm{kg}$ group, $\mathrm{Fs}(1,11)=5.07$ and $5.63, \mathrm{p}<.05$; comparing the $2.0-\mathrm{mg} / \mathrm{kg}$ group to the $2.5-\mathrm{mg} / \mathrm{kg}$ group yields $F(1,11)=$ $10.45, \mathrm{p}<.01$, and the $2.5 \cdot \mathrm{mg} / \mathrm{kg}$ group to the $3.0-\mathrm{mg} / \mathrm{kg}$ group yields $\mathrm{F}(1,11)=23.12, \mathrm{p}<.01]$. This shows that the peak effect of the drug occurs at the $2.5 \cdot \mathrm{mg} / \mathrm{kg}$ dose and that at higher doses the effect of the drug decreases.

These results replicate the Lyons et al (1973) finding of an elimination of the peak shift and a progressive reduction of the area shift under the drug, chlorpromazine. As with the earlier study, the present study showed a clear dose-dependent effect and no 
tendency for the discrimination to break down under the drug. In reference to this latter point. the rats actually responded more to $\mathrm{S}$-. but not reliably so, in the saline control conditon than under the drug. This suggests that, as was the case with the pigeon, the process that maintains discrimination performance is different from the process that produces the peak and area shifts. The presence of good discrimination performance with no peak shift and a substantial reduction in the area shift under the drug in both the rat and the pigeon suggests that the process that produces and maintains such performance may be similar in both species. It is also interesting to note that in both the present study and the earlier Lyons et al (1973) study. the area-shift measure seemed to be a better index of the effect of the drug than the presence or absence of the peak shift. The area-shift measure suggests that the effect of the drug is on a continuum rather than all or none, as the peak-shift measure would indicate. In addition to showing a graded effect of the drug. the area-shift measure also showed that the peak effect of the drug occurred not at the highest dose level of the drug, but at the next to highest dose. The peak-shift measure masked this effect in both studies. Therefore, we feel that the area-shift measure probably presents a better picture of the effect of chlorpromazine on a past discrimination-generalization gradient than does a measure of presence or absence of the peak shift.

The results of the present study suggest that the process that produces the peak shift is different from the process that maintains discrimination performance; however, one could argue that the drug weakens inhibition only enough to reduce the peak and area shifts but not enough to cause a breakdown in discrimination performance. If this were the case, one would expect the weakened inhibition to increase the tendency for rats under the drug to respond to the floor positions 5 and 10 deg to the left of S+ (i.e., the two test stimuli between the $\mathrm{S}+$ and the $\mathrm{S}-$ ) over their rate to the same two stimuli in the saline control condition. Reduced responding to these two stimuli is thought to result from a generalization of inhibition from the $\mathrm{S}-$, and any reduction in that inhibition should be reflected in an increase in the response rate to these two stimuli. However, this was not the case; in fact, the mean percent of total responses to these two stimuli was higher, but not reliably so. in the saline control condition than under the influence of the drug. Therefore, an argument suggesting that weakened inhibition produced the results of the present study is not consistent with the results of the present study.

The results of the present study, combined with the earlier work. raise serious questions concerning Terrace's (1963. 1966, 1972) position that the inhibitory processes which maintain discrimination performance also produce the peak shift. Clearly, in the present study, this was not the case. For many Ss, the drug eliminated the peak shift and reduced the area shift, but had little or no effect on discrimination performance, even though there were three "S- $s$ " used and strong responding to any one of them would have reflected a breakdown in discrimination performance. If the same inhibitory process were producing all three, i.e., discrimination performance and the peak and area shifts, then elimination of inhibition in one case would be reflected in the other two.

\section{REFERENCES}

Bloomfield, T. M. Behavioral contrast and the relative reinforcement frequency in two multiple schedules. Journal of the Experimental Analy'sis of Behavior. 1967, 10, 151-158.

Hanson, H. M. Effects of discrimination training on stimulus generatization. Journai of Experimental Psychology, 15\%, 58, 321-334.

Lyons, J., Klipec, W. D., \& Steinstultz, G. The effect of chlorpromazine on discrimination performance and the peak-shift. Physiological Psychology, 1973, in press.

Riccio, D. C., Urda, M., \& Thomas, D. R. Stimulus control in pigeons based on proprioceptive stimuli from floor inclination. Science, 1966, 153, 434-436.

Terrace, H. S. Errorless discrimination learning in the pigeon: Effects of chlorpromazine and imipramine. Science. 1963, $140,319$.

Terrace, H. S. Stimulus control. In W. K. Honig (Ed.), Operant behavior: Areas of research and application. New York: Appleton-Century-Crofts, 1966.

Terrace, H. S. By products of discrimination learning. In G. T. Bower and J. T. Spence (Eds.), Learning and motivation. New York: Academic Press, in press.

(Received for publication August 14, 1972; revision accepted February 20,1973.) 